\title{
Controlled cold rolling effect on microstructure and mechanical properties of Ce-modified SAF 2507 super duplex stainless steel
}

\author{
Tian Zhou ${ }^{1}$, Yi Xiong ${ }^{1,2 *}$, Yun Yue ${ }^{3}$, Yan $\mathrm{Lu}^{1}$, Yan-na Chen ${ }^{1}$, Tian-tian $\mathrm{He}^{3}$, \\ Feng-zhang Ren ${ }^{1,2}$, Harishchandra Singh ${ }^{4}$, Jukka Kömi ${ }^{5}$, Marko Huttula ${ }^{4,1}$, Wei Cao ${ }^{4,6}$ \\ ${ }^{1}$ School of Materials Science and Engineering, Henan University of Science and Technology, \\ Luoyang 471023, Henan, China \\ ${ }^{2}$ Collaborative Innovation Center of Nonferrous Metals, Luoyang 471023, Henan, China \\ ${ }^{3}$ National United Engineering Laboratory for Advanced Bearing Tribology, Henan University of \\ Science and Technology, Luoyang 471023, Henan, China \\ ${ }^{4}$ Nano and Molecular Systems Research Unit, University of Oulu, FIN-90014, Finland \\ ${ }^{5}$ Materials and Mechanical Engineering, Center for Advanced Steels Research, University of Oulu, \\ FIN-90014, Finland
}

${ }^{6}$ School of Mechanical and Automotive Engineering, Anhui Polytechnic University, Wuhu 241000, Anhui, China

\begin{abstract}
Controlled cold rolling impacts on microstructure and mechanical properties of the rare earth Ce-modified SAF 2507 super duplex stainless steel (SDSS) are investigated towards a better application and development prospective over the pristine SDSS. Rolling was performed at room temperature with the deformation level in a range of $30 \%-90 \%$. A large amount of dislocations into the ferrite phase turned out, and their density increased with the deformation. While, emergence of dislocation plugs group, ferrite grains get refined to nanometer scale during the
\end{abstract}


deformation process. In addition to deformed bands within austenite, formation of $\alpha^{\prime}$-martensitic phases and significant increment in their volume fraction are detected and attributed to deformation-induced martensitic transformation. Elongation of the ferrite and austenite microstructures along the deformation direction under the action of high strain also resulted in fibers formation gradually. Correspondingly, significant increase in the strength index while decrement in the plasticity index are observed. Moreover, cold rolling deformation not only affects the tensile fracture morphology but also switches it from a typical ductile to a ductile and quasi-cleavage mixed fracture.

Keywords: Super duplex stainless steel; Cold rolling; Microstructure; Mechanical properties; Deformation-induced martensitic transformation 


\section{Introduction}

In state-of-the-art duplex stainless steel SAF 2507, super duplex stainless steel (SDSS) has been endowed with high strength and good wear resistance [1,2], good plasticity and toughness [2,3], excellent resistance to intergranular corrosion and chloride corrosion [4-8], and good weldability [9-11]. These merits offer its wide utilization in the fields of oil and gas resources, chemical industry, machinery, construction etc. Despite these merits, its production costs have remained high as SAF 2507 SDSS contains high contents of expensive alloying elements such as nickel and molybdenum. Meanwhile, due to the huge differences in composition, microstructure and mechanical properties between the austenite and ferrite phases, and their extremely complex plastic deformation behavior, the hot working difficulty of the alloy increases correspondingly, and usually leads to poor surface quality of finished products [12-16]. Such poor surface integrity of hot-workpiece limits its application in industrial production.

This work aims to design a new type of SDSS by appropriate addition of rare earth (RE) element $\mathrm{Ce}$ and increasing nitrogen $(\mathrm{N})$ content on the basis of the SAF 2507 SDSS from the perspective of reducing production costs and improving thermal processing performances. An addition of rare earth element $\mathrm{Ce}$ can enhance the fatigue property, wear resistance, strength and toughness of SAF 2507 SDSS, and improve its high temperature plasticity, welding performance and atmospheric corrosion resistance significantly. Meanwhile, the grain refinement combined with the morphology and distribution change of inclusions turned out and yielded better microstructure optimizations and mechanical performances $[17,18]$. The increase of $\mathrm{N}$ content can also reduce the usage amount of precious $\mathrm{Ni}$ comparatively, thus lowering the production cost $[19,20]$. Therefore, rare earth Ce-modified SAF 2507 SDSS shows better application prospect and 
wider development space over the parent SAF 2507 SDSS.

In order to further improve the surface processing quality and precision of SDSS workpieces, cold rolling process has been widely used in industrial practice because of its high dimensional precision, good surface quality, high strength and hardness [21]. Most of the reports are focused on the microstructure and mechanical properties of SDSS after cold rolling of SAF 2205 SDSS [22-24] except a few reports on SAF 2507 SDSS. Though hot workability was scarcely reported for the rare earth Ce modified SAF 2507 SDSS [14,25], microstructure and mechanical properties remain unknown for the cold rolled SDSS. This work probes into rare earth Ce-modified SAF 2507 SDSS by room temperature (RT) cold rolling under different level of deformation. By means of several measurements and data analysis, the microstructure and mechanical properties of rare earth Ce-modified SAF 2507 SDSS treated under different deformation level are systematically studied to provide the theoretical basis and experimental support for the low-cost production and efficient development of new SDSS.

\section{Material and Methods}

\subsection{Material}

In order to get the rare earth Ce-modified SAF 2507 SDSS ingot for this study, mixed ingredients including Fe-Ce intermediate alloy sealed by pure iron pipe were melted in $150 \mathrm{~kg}$ intermediate frequency induction furnace [26] and poured into a cast mould. The chemical composition of obtained ingot (wt. \%) is listed in table 1.

The Ce-modified SAF 2507 SDSS ingot was forged and hot-rolled into $500 \times 10 \times 17 \mathrm{~mm}^{3}$ plates. The block-shaped specimens were wire-cut to $80 \times 17 \times 17 \mathrm{~mm}^{3}$, heated to $1050{ }^{\circ} \mathrm{C}$, held for $60 \mathrm{~min}$ and then quickly quenched in water. Finally, the Ce-modified SAF 2507 SDSS 
specimens in solid solution state were obtained [27].

\subsection{Experimental Methods}

A three-phase asynchronous two-high rolling mill LG-300 was used to conduct RT cold rolling with the deformation amounts of 30\%, 50\%, 70\% and 90\%, respectively for four groups of solid solution of Ce-modified SAF 2507 SDSS specimens. Ce-modified SAF 2507 SDSS specimens with different deformation amounts were obtained. To obtain these set of specimens, the rolling speed and the single rolling reduction were used as $0.2 \mathrm{~m} / \mathrm{s}$ and $5 \%$, respectively.

The specimens were mechanically polished and electro-etched in $30 \mathrm{~g} \mathrm{KOH}+50 \mathrm{~mL} \mathrm{H}_{2} \mathrm{O}$ solutions. Optical microstructure was observed under an OLYMPUSPMG3 microscope and Vickers hardness was measured by MH-3 microhardness tester. The specimens with the size of 10 $\times 10 \times 0.5 \mathrm{~mm}^{3}$ were intercepted and thinned to about $50 \mu \mathrm{m}$ by using one-sided grinding of waterproof abrasive paper for transmission electron microscopy (TEM) observation. Then the sheet of $3 \mathrm{~mm}$ was pressed out in the mould and thinned on a Gatan 691 thinning instrument. A JEM-2010 transmission electron microscope was employed for the microstructure detection.

The plate-like tensile specimens of each group were prepared according to the dimension as shown in Fig. 1. Electronic universal testing machine UTM4104 was used to evaluate the mechanical properties. After tensile test, the fracture morphology of micro-tensile specimens were observed by a Hitachi S-4800 scanning electron microscope (SEM).

D8 X-ray diffractometer (XRD) was used to study martensite transformation of the cold rolled specimens, and also the strain induced due to cold rolling deformation. The diffraction peaks of (111), (200), (220) of the austenite phase ( $\gamma$ ) and (110), (200), (211) of the ferrite phase $(\alpha)$ were selected, respectively [28]. The formula for calculating the volume fraction of i ( $\alpha$ or $\gamma)$ 
phase $V_{\mathrm{i}}$ reads:

$$
V_{\mathrm{i}}=\frac{\frac{1}{\mathrm{n}} \sum_{\mathrm{j}=1}^{\mathrm{n}} \frac{I_{\mathrm{i}}^{\mathrm{j}}}{R_{\mathrm{i}}^{\mathrm{j}}}}{\frac{1}{\mathrm{n}} \sum_{\mathrm{j}=1}^{\mathrm{n}} \frac{I_{\alpha}^{\mathrm{j}}}{R_{\alpha}^{\mathrm{j}}}+\frac{1}{\mathrm{n}} \sum_{\mathrm{j}=1}^{\mathrm{n}} \frac{I_{\gamma}^{\mathrm{j}}}{R_{\gamma}^{\mathrm{j}}}}
$$

Here, $\mathrm{n}, \mathrm{I}$ and $\mathrm{R}$ are the number of diffraction peaks, diffraction peak intensity factor and material scattering factor of the corresponding phases ( $\alpha$ and $\gamma$ ), respectively. The mean value and mean square error of three measurements at different positions were taken as the value and error of martensite content in corresponding specimens.

\section{Results}

\subsection{Microstructure Evolution}

\subsubsection{Metallographic structure}

Figure 2 depicts optical micrographs of solid-solution and cold rolled Ce-modified SAF 2507 SDSS. The dark black region denotes the ferrite phase while the bright white region refers to the austenite phase. These phases (austenite and ferrite) also seem to have similar quantities in the SAF 2507. The grains show irregular shapes along with grain boundaries, as in Fig. 2(a). Optical micrographs of Ce-modified SAF 2507 SDSS sample treated with $30 \%$ and $50 \%$ cold rolled deformation are shown in Figs. 2(b) and (c), respectively. Ferrite and austenite grains are continuously compressed and elongated along the rolling direction during the cold rolling deformation process. Increase in the deformation gives rise to fragmented grains with refined morphology along with denser distributions of ferrite and austenite phases. Under the action of large strain (detailed more in section 3.2), the rod-like grains gradually arise from the original irregular shapes [29,30]. Figs. 2(d) and (e) show the optical micrographs of Ce-modified SAF 2507 SDSS deformed by $70 \%$ and $90 \%$ cold rolling, which indicates that the ferrite and austenite 
grains are elongated constantly with the increase of deformation degree and distributed alternately in the form of stripes. Because of the large grain size difference between ferrite and austenite phases in the solid solution state, the bandwidth of ferrite and austenite grains is not uniform. The wide-band grains are mainly affected by the normal stress and the bandwidth decreases with the increasing deformation. While, the narrow ones are prone to be affected by shear stress and bent into wavy shape. Furthermore, the necking phenomenon along with fracture takes place gradually and the microstructure interlaced acicular structure and transforms into fiber texture [29-31]. Meanwhile volume fraction of austenite phase decreases in the process of cold rolling deformation (see section 3.2). This is because austenite belongs to the metastable phase which could be transformed to martensite when chemical driving force in addition to mechanical driving force reaches a critical point for martensite transformation under high applied stress. Also, the content of austenite phase decreases due to the deformation-induced martensite transformation in Ce-modified SAF 2507 SDSS [30,31]. The bandwidth distribution of grains under 90\% cold rolling deformation is shown in Fig. 2(f). This reveals that both the austenite and ferrite have been refined down to nano-scale under the high strain (see section 3.2). However, the bandwidth of austenite grains is smaller than that of ferrite grains. This underlying mechanism can be explained by deformation-induced martensite transformation in austenite, which is separated by newly formed martensite and fragmented continuously under the action of stress.

\subsubsection{TEM observation}

Figure 3 shows the observed TEM images of cold rolled Ce-modified SAF 2507 SDSS at room temperature. Figs. 3(a) (d) show the microstructure of Ce-modified SAF 2507 SDSS with $30 \%$ cold rolling deformation. The original grain boundary between the austenite and ferrite 
phases can be clearly noticed in Fig. 3(a). Many dislocations present on the ferrite phase. High-density dislocations interact with each other during the cold rolling deformation, resulting in formations of dislocation tangle and dislocation wall. In the austenite phase, there are many deformation bands between which high density dislocation tangle stays. Fig. 3(b) also shows many deformation bands oriented in different directions in the austenite phase. The intersection sites of deformation bands with different directions provide favorable nucleation locations for deformation-induced martensite transformation. The bright and dark field images of deformation-induced martensite are illustrated in Fig. 3(c) and (d). Most of the deformation-induced martensite debuts at the intersection locations of deformation bands in different directions. Figs. 3(e) (h) show the TEM images of Ce-modified SAF 2507 SDSS under 90\% cold rolling deformation. In Fig. 3(e), the dislocation density in the ferrite increases with the increase in deformation. A large amount of dislocations twine and pile up as evenly-formed groups. The grain boundaries are blurred. Meanwhile, the fragmented ferrite is combined with ring-like diffraction spots (see Fig. 3(f)) indicating that the ferrite grains in this state have been refined to nanometer scale [30,31]. As expected, more volume fraction of martensite has been observed compared to 30\% deformation, as illustrated in Figs. 3(g) and (h). This indicates the amount of deformation-induced martensite increases significantly under $90 \%$ cold rolling deformation.

\subsection{Quantitative Evaluation by XRD}

The XRD patterns of Ce-modified SAF 2507 SDSS after different level of cold rolling deformation treatment are depicted in Fig. 4. Mainly three types of variations in the XRD peak structure have been observed with increase of rolling deformation--the change in peak intensity, the change in peak width and slight shift in the peak position towards lower $2 \theta$. As can be seen, 
the diffraction intensities of austenite phase decrease, and the diffraction peaks of (200), (311) and (222) crystal plane disappear completely except for (111) and (220). This is ascribed to significant decrease in the volume fraction of austenite phase considering the deformation-induced martensitic transformation of austenite during cold rolling process. Disappearance of XRD peaks against deformation also indicates the possible grain orientation along the rolling direction and the grains which follow Bragg's law i.e. $2 \mathrm{~d} \sin \theta=\mathrm{n} \lambda$ results in diffracted peaks only. The results of phase content calculation according to equation (1) indicate the volume fractions of austenite and ferrite phases in the solid solution of Ce-modified SAF 2507 SDSS are 51.6\% and 48.4\% before cold rolling, respectively. With increasing deformation up to $90 \%$, the volume fraction of austenite phase in Ce-modified SAF 2507 SDSS has been reduced to $14.8 \%$. The decrease of austenite phase volume fraction corresponds to the volume fraction of deformation-induced martensite phase. The calculated volume fraction of martensite phase is $36.8 \%$ and the relative transformation rate is $71.3 \%$. Chen et al., also found that the deformation-induced martensitic occurred in SAF 2507 SDSS after shot peening, and the martensite transformation increased with the increase of peening strength. The corresponding transformation mechanism has been attributed as $\gamma \rightarrow$ austenite twins $\rightarrow \alpha^{\prime}$-martensite [32]. Pramanik et al., confirmed that deformation-induced martensite also occurred in SAF 2205 SDSS during cold rolling, and the martensite transformation increased with the increase of deformation [23]. The other two changes in the XRD patterns (i.e. peak shape and position) are highly correlated with the strain generated in these specimens while cold rolling deformation. The microstrains are basically the local distortions of the crystal lattice, such as dislocations (as can be visualized in section 3.1.2) which cause variations in the lattice parameters and therefore a broadening of the diffraction peaks. The instrumental settings and 
finite crystallite size have also been reported to affect the XRD peak shape [33].

To get actual numbers and statistics, diffraction peak analysis has been performed using Williamson-Hall (W-H) method to estimate microstrain variation against cold rolling deformation. One can also calculate the average crystallite size using W-H analysis which is not a focus of research here though. As per $\mathrm{W}-\mathrm{H}$ method the individual contribution to the broadening of diffraction peaks can be expressed as [34]:

$$
\begin{aligned}
& \left(\beta_{\text {observed }}\right)^{2}=\left(\beta_{\text {instrument }}\right)^{2}+\left(\beta_{\text {strain }}\right)^{2}+\left(\beta_{\text {size }}\right)^{2} \\
& \beta^{2}=\left(\beta_{\text {observed }}\right)^{2}-\left(\beta_{\text {instrument }}\right)^{2} \\
& \beta^{2}=4 \varepsilon^{2} \tan ^{2} \theta+\left(\frac{0.9 \lambda}{D \cos \theta}\right)^{2} \\
& \beta^{2} \cos ^{2} \theta=4 \varepsilon^{2} \sin ^{2} \theta+\left(\frac{0.9 \lambda}{D}\right)^{2}
\end{aligned}
$$

where $\beta$ is the FWHM of the Bragg peaks (in radian), $2 \theta$ the Bragg angle and $\lambda$ the

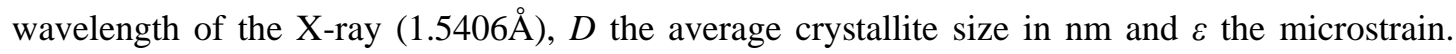
Also, $\beta_{\text {instrument }}$ is the instrumental broadening calculated from the diffraction broadening of the given original sample. The obtained data has been used to construct a linear plot of $\beta^{2} \cos ^{2} \theta$ as a function of $4 \sin ^{2} \theta$ (see equation (2-5)) to get the slope of the best fit straight line which gives $\varepsilon^{2}$. The intercept on Y-axis provides the average crystallite size, D. Followed by some typical calculations, microstrain as a function of deformation is plotted in figure 5. As can be seen, linear variation of strain as a function of deformation, and slightly different level of microstrain for the two phases have been observed. The latter variation may be understood by the fact of metastable and stable phase criteria of austenite and ferrite phases, respectively.

The martensite transformation curve of Ce-modified SAF 2507 SDSS with different cold rolling deformation is also shown in Fig. 6 (obtained using equation 1). The metastable austenite 
phase of the Ce-modified SAF 2507 SDSS undergoes deformation induced martensite transformation with the increase in deformation, and the volume fraction of austenite phase decreases against increase in martensite phase. It is well known that the deformation-induced martensite phase transition is usually affected by strain, stress state, strain rate, deformation temperature and other factors synergistically. Typically, larger strains normally generate more defects in the material, and lead to easier martensite nucleation at the defective location $[31,35]$. The phenomenon wass also observed in the case of $316 \mathrm{~L}$ stainless steel studies, where the martensite nucleation mainly occurred at the junction of shear bands. Therein, a large strain was needed to produce great quantities of martensite transformations [36]. Under the current experimental conditions, with the increase in deformation amount, many deformation bands are continuously generated in austenite phase with low stacking fault energy. The intersections of deformation bands oriented in different directions provide abundant hosts for the nucleation of martensite. At the same time, the large plastic deformation provides additional mechanical driving force for the martensite phase transition and compensates for the required part of chemical driving force to grow the martensite at the defect locations. Therefore, the larger the deformation, the higher the volume fraction of deformation-induced martensite will be, as shown in Figs. 3 (d), (h) and Fig. 6.

\subsection{Mechanical Property}

\subsubsection{Microhardness}

The microhardness of Ce-modified SAF 2507 SDSS as a function of cold rolling deformation deployed at room temperature is presented in Figure 6. The microhardness was increased $~ 50 \%$, from $374 \mathrm{HV}$ of the solid-solution treated Ce-modified SAF 2507 SDSS to $561 \mathrm{HV}$ of the one 
after $90 \%$ deformation. The significant increase of the mechanical property can be attributed to the following aspects. Interactions of various dislocations easily took place due to constant dislocation multiplications in the ferrite structure of the RE-modified SDSS and increased dislocation density with the increase of deformation level. These interactions further lead to dislocations of cells or subgrain boundaries due to dislocation cross slipping, and the ferrite phase tended to be refined to nanometer-scaled grains which greatly contribute to the material strengthening. Because the stacking fault energy of austenite is lower than that of ferrite, the cross slip of dislocation in austenite structure is relatively more difficult. Deformation-induced martensitic occurs easily in austenite structure during deformation and the hard-martensitic phase also plays a major role in strengthening. As a result of ferrite grain refinement and martensite phase formation induced by austenite deformation, the hardness of Ce-modified SAF 2507 SDSS increases with the deformation, which is consistent with the change trend of martensite transition [23]. It is further noted that the observed hardness is still greater than the same observed for $70 \%$ cold deformation. This is due to the high-volume percent of deformation-induced martensite under the same condition. The difference of hardness increment values indicate that austenite and ferrite phases vary differently with the degree of deformation.

\subsubsection{Strength and Plasticity}

Investigated tensile properties of cold rolled Ce-modified SAF 2507 SDSS with different degree of deformation is also shown in Figure 7. The yield strength, ultimate tensile strength and elongation of Ce-modified SAF 2507 SDSS in solid solution state are $578 \mathrm{MPa}, 781 \mathrm{MPa}$ and $15.2 \%$, respectively. With the increase in deformation to $90 \%$, the yield strength and ultimate tensile strength are observed to be $1426 \mathrm{MPa}$ and $1557 \mathrm{MPa}$, respectively while the elongation has 
been decreased to $3.1 \%$. In the process of cold rolling deformation, there exists deformation-induced martensite transformation in the austenite phase of the Ce-modified SAF 2507 SDSS and many dislocation substructures to coordinate severe plastic deformation in the ferrite phase. With the increase in deformation amount, the intensified dislocation multiplication and accumulation result in the occurrence of dislocation jog and pile-ups to impede dislocation movement. Under the action of large strain, ferrite phases are fragmented drastically, and the corresponding grain size is refined to nanometer scale. Under the combined action of deformation-induced martensite transformation and grain refinement, the remarkable increased deformation resistance of Ce-modified SAF 2507 SDSS increases gives rise to a significant increase in its strength and hardness [37]. Also, since the martensite phase is a hard phase, the corresponding plasticity deteriorates sharply with the increase of the martensite volume fraction $[22,38]$.

\subsection{Fracture Morphology}

Figure 8 shows the fracture morphology of micro tensile specimens of Ce-modified SAF 2507 SDSS under different cold rolling deformation at room temperature. The large and deep dimples in the tensile fracture surfaces of Ce-modified SAF 2507 SDSS gradually become small and shallow with the increase in deformation, and the mean dimple size decreases gradually to about $3 \mu \mathrm{m}$ when the deformation was increased to $90 \%$. This can be ascribed to the increased dislocation density in ferrite grains by cold rolling deformation and the intensified interaction between dislocations, resulting in dislocation entanglement or dislocation jog that hinders further movement of dislocations. Under the action of large strain, ferrite grains are severely broken up and refined to the nanometer scale [30,31]. Cleavage planes can be observed in the tensile fracture 
surfaces of all the specimens with different deformation and the area occupied by the cleavage plane increases obviously with the increase of deformation. At the same time, many fine microcracks appear near some cleavage planes. This is because the cold rolling process causes the deformation induced martensite transformation in the austenite phase of the Ce-modified SAF 2507 SDSS, and the volume fraction of transformed martensite increases obviously with the increase of deformation. During tensile process, the fracture morphology of austenite phase with good plasticity presents dimples of ductile fracture compared to cleavage planes of hard and brittle martensite phase. Micro-cracks originate from the hard and brittle martensite phase under applied stress and the cracks continue to expand until fracture occurs [39]. This clearly indicates that with increase in deformation, the fracture mode of Ce-modified SAF 2507 SDSS changes from the typical ductile fracture before cold rolling deformation to mixed characteristic of ductile and quasi-cleavage mixed fracture after cold rolling deformation.

\section{Discussion}

In general, the microstructure evolution of the Ce-modified SAF 2507 SDSS undergoes the following stages subjected to the cold rolling at different levels of deformation: The ferrite and austenite microstructures were elongated along the deformation direction. With the increase in deformation level, they gradually turned up as laths. The ferritic phase with a high stacking fault energy mainly coordinates deformation by dislocation slip while austenite phase with low stacking fault energy by mechanical twins. This is because the stacking fault energy determines the deformation mechanism of materials [40-42]. In addition to the metastable austenite phase, deformation induced martensite phases were also introduced in the SDSS, as allowed by the deformation mechanism. Therefore, the ferrite and austenite phases in Ce-modified SAF 2507 
SDSS have get through deformation processes and hence complicated the microstructure evolution during the cold rolling deformation. Also due to the high stacking fault energy of bcc ferrite phase, high density dislocations are germinated in the ferrite phase to coordinate the plastic deformation. Further, the high-density dislocations in the ferrite phase interact with each other. As a result, the dislocation wall and the dislocation cell or dislocation plug product group are formed, and observed the subgrains. These subgrains were further transformed into the nanoscaled grains under the action of large strain. Rys et al., also found ferritic ring-like diffraction spots, confirming that the ferrite grains followed by nano-crystallization under cold rolling impact [31]. With a low stacking fault energy, the fcc austenite phase belongs to a less slip system than the ferrite. Therefore, large number of deformation bands occur in the austenite phase to coordinate the plastic deformation. The deformation bands interaction in different directions, or in other words the interaction between deformation bands and dislocations, provide the nucleation positions for martensitic transformation. The deformation-induced martensitic transformation occurs in austenite phase. The austenite-martensite transformation in Ce-modified SAF 2507 SDSS during the cold rolling is similar to that of single-phasic austenite stainless steel [43-45]. These studies show that the transformation induced by deformation mainly happens in the austenite phase, because as the degree of deformation increases more transformation variables of deformation-induced martensite turn out.

Cold rolling of SDSS produces two forms of metastable austenite phases, the $\varepsilon$-martensite (hcp) and $\alpha^{\prime}$-martensite (bcc). Herein, $\alpha^{\prime}$-martensite phase is clearly visible in XRD patterns (Fig. 4) as well as in TEM diffractions (Fig. 3). However no $\varepsilon$-martensite phase can be observed. This might be due to the fact that the transformation mechanism of deformation-induced martensite is 
determined by the stacking fault energy of SDSS. If the energy is $\leq 18 \mathrm{~mJ} / \mathrm{m}^{2}$, the transformation route follows $\gamma \rightarrow \varepsilon$-martensite $\rightarrow \alpha^{\prime}$-martensite. With the energy $>18 \mathrm{~mJ} / \mathrm{m}^{2}$, the route turns to $\gamma \rightarrow$ austenite twins $\rightarrow \alpha^{\prime}$-martensite [46,47]. With a stacking fault energy of $22 \mathrm{~mJ} / \mathrm{m}^{2}$ [48], the present SAF 2507 SDSS tends to have a deformation-induced martensite transformation via the second route of $\gamma \rightarrow$ austenite twins $\rightarrow \alpha^{\prime}$-martensite.

The level of cold rolling deformation shows an important impact on the mechanical properties of Ce-modified SAF 2507 SDSS. The strength and hardness of Ce-modified SAF 2507 SDSS increase with the deformation gradually, but the plasticity drops significantly. This is attributed to the following three aspects: (1) The deformation-induced martensitic transformation took place at the metastable austenite phase and improved the hardness of matrix; (2) The high-density dislocations continue to grow and accumulate in the ferritic phase and result in work hardening. (3) However, due to the content decrease of the austenite with good plasticity, the overall plasticity of the rolled SDSS becomes smaller.

The fracture morphology also changed after the cold rolling. Due to the good plasticity of ferrite phase, the fracture forms honeycomb dimple after tensile fracture [49]. With the increase of deformation level, the large and deep dimples in the tensile fracture surface of Ce-modified SAF 2507 SDSS gradually become small and shallow. This is because ferrite grains were gradually broken and refined into nanocrystalline grains during cold rolling deformation, as clearly seen in micrographs (Figs. 2 and 3). Meanwhile, the cleavage plane became visible in the tensile fracture surfaces, and more intensive with the increase of deformation. This is in accordance to a previous cryorolling study of $316 \mathrm{LN}$ stainless steel [50]. After deformation-induced transformation of the $316 \mathrm{LN}$ stainless steel from the austenite to martensite, the tensile fracture morphology changed 
from a typical ductile fracture to ductile and quasi-cleavage mixed fracture.

\section{Conclusion}

A systematic controlled cold rolling effect on the microstructure and mechanical properties of Ce-modified SAF 2507 SDSS has been investigated. Following conclusions are drawn from the work:

1. During the cold rolling deformation from $30 \%$ to $90 \%$, ferrite in Ce-modified SAF 2507 SDSS coordinates severe plastic deformation which are mainly caused by dislocation slip and ferrite grain size refined to nanometer scale under large strain. Austenite mainly coordinates deformation by deformation band and deformation-induced martensitic transformation. The volume fraction of deformation-induced martensite increases significantly with the increase in deformation.

2. With the increase in deformation, the strength of Ce-modified SAF 2507 SDSS increases rapidly under the synergistic effect of ferrite nanocrystals and deformation induced martensite transformation in austenite. In contrast, the elongation of Ce-modified SAF 2507 SDSS decreases dramatically. When the deformation is $90 \%$, the elongation drops to $3.1 \%$, and the decrease is about 79.6\%; however, the hardness, yield strength and ultimate tensile strength of Ce-modified SAF 2507 SDSS increases by $51.5 \%, 146.7 \%$ and $99.4 \%$, respectively, to $561 \mathrm{HV}, 1426 \mathrm{MPa}$, and $1557 \mathrm{MPa}$.

3. The tensile fracture morphology of Ce-modified SAF 2507 SDSS gradually changed from typical ductile fracture (before deformation) to mixed characteristic of ductile and quasi-cleavage mixed fracture (after deformation).

\section{Acknowledgement}


This work is supported by the National Natural Science Foundation of China under grants Nos. U1804146 and 51801054, and by the Program for Science, Technology Innovation Talents in Universities of Henan Province (17HASTIT026), Education Department of Henan Province (16A430005) and the Science and Technology Innovation Team of Henan University of Science and Technology (2015XTD006). Financial supports from the Academy of Finland [311934] and Anhui Provincial Grant for high-level platform construction are also acknowledged.

\section{References}

[1] Marques F , Silva W M D , Pardal J M , et al. Influence of heat treatments on the micro-abrasion wear resistance of a superduplex stainless steel[J]. Wear, 2011, 271(9):1288-1294.

[2] Ahiale G K , Kim D H , Yang W J , et al. Change of precipitation behavior and impact toughness with depths in quenched thick SAF 2507 super duplex stainless steel[J]. Metals and Materials International, 2018, 24:738-745.

[3] Hilders $\mathrm{O}$, Zambrano $\mathrm{N}$. The effect of aging on impact toughness and fracture surface fractal dimension in SAF 2507 super duplex stainless steel[J]. Journal of Microscopy and Ultrastructure, 2014, 2(4):236-244.

[4] Hong J F, Han D, Tan H, et al. Evaluation of aged duplex stainless steel UNS S32750 susceptibility to intergranular corrosion by optimized double loop electrochemical potentiokinetic reactivation method[J]. Corrosion Science, 2013, 68(1):249-255.

[5] Vahid H , Leif K, Sten W, et al. Effect of sigma phase morphology on the degradation of properties in a super duplex stainless steel[J]. Materials, 2018, 11(6):933.

[6] Lee J S, Park Y S. Effects of solution annealing temperature on the galvanic corrosion behavior of the super duplex stainless steels[J]. Journal of Materials Engineering and Performance, 2013, 22(2):557-562.

[7] Pardal J M, Tavares S S M, Fonseca M P C, et al. Study of deleterious phase precipitation under continuous cooling of superduplex stainless steel UNS S32750[J]. Materials Science and Technology, 2013, 28(3):295-302. 
[8] Giourntas L, Hodgkiess T, Galloway A M . Comparative study of erosion-corrosion performance on a range of stainless steels[J]. Wear, 2015, 332-333:1051-1058.

[9] Giorjao R A R , Pereira V F , Terada M , et al. Microstructure and mechanical properties of friction stir welded 8, mm pipe SAF 2507 super duplex stainless steel[J]. Journal of Materials Research and Technology, 2018, 340:7.

[10] Hosseini V A , Valiente Bermejo, M. Asunción, GaRdstam J , et al. Influence of multiple thermal cycles on microstructure of heat-affected zone in TIG-welded super duplex stainless steel[J]. Welding in the World, 2016, 60(2):233-245.

[11] Tavares S S M , Pardal J M , Lima L D, et al. Characterization of microstructure, chemical composition, corrosion resistance and toughness of a multipass weld joint of superduplex stainless steel UNS S32750[J]. Materials Characterization, 2007, 58(7):610-616.

[12] Lin G, Zhang Z X , Song H W , et al. Investigation of the hot plasticity of duplex stainless steel[J]. Journal of Iron and Steel Research International, 2008, 15(6):80-86.

[13] Mishra M K , Balasundar I , A. G. Rao, et al. On the high temperature deformation behaviour of 2507 super duplex stainless steel[J]. Journal of Materials Engineering and Performance, 2017, 26(2):802-812.

[14] Wang X F, Chen W Q. Influence of cerium on hot workability of 00Cr25Ni7Mo4N super duplex stainless steel[J]. Journal of Rare Earths, 2010, 28(2):295-300.

[15] Iza-Mendia A, Piñol-Juez A, Urcola J J, et al. Microstructural and mechanical behavior of a duplex stainless steel under hot working conditions[J]. Metallurgical and Materials Transactions A, 1998, 29(12):2975-2986.

[16] Mapelli C, Barella S, Mombelli D, et al. Comparison between symmetric and asymmetric hot rolling techniques performed on duplex stainless steel 2205[J]. International Journal of Material Forming, 2013, $6(3): 327-339$.

[17] Kim S T, Jeon S H, Lee I S , et al. Effects of rare earth metals addition on the resistance to pitting corrosion 
of super duplex stainless steel[J]. Corrosion Science, 2010, 52(6):1897-1904.

[18] Fu X X, Shan A D, Zhou C D, et al. Effect of rare-earth element Ce on hot deformation capacity of super duplex stainless steel[J]. Materials for Mechanical Engineering, 2009, 33(10):9-12.

[19] Weber L, Uggowitzer P J. Partitioning of chromium and molybdenum in super duplex stainless steels with respect to nitrogen and nickel content[J]. Materials Science and Engineering A, 1998, 242(1):222-229.

[20] Sinan N , Cheang K H , Lo K H. Some aspects of using stainless steel as concrete reinforcing bars and recent developments in high nitrogen, low nickel stainless steels[J]. Recent Patents on Mechanical Engineering, 2011, $4(3): 234-242$.

[21] Fargas, Akdut, Anglada, et al. Reduction of anisotropy in cold-rolled duplex stainless steel sheets by using sigma phase transformation[J]. Metallurgical and Materials Transactions A, 2011, 42(11):3472-3483.

[22] Breda M, Brunelli K, Grazzi F, et al. Effects of cold rolling and strain-induced martensite formation in a SAF 2205 duplex stainless steel[J]. Metallurgical and Materials Transactions A, 2015, 46(2):577-586.

[23] Pramanik S, Bera S, Ghosh S K. Influence of cold rolling on microstructural evolution in 2205 duplex stainless steel[J]. Steel Research International, 2014, 85(5):776-783.

[24] Kumar A, Khatirkar R K, Chalapathi D, et al. Microstructure and texture development during cold rolling in UNS S32205 and UNS S32760 duplex stainless steels[J]. Metallurgical and Materials Transactions A, 2017, 48(5):2349-2362.

[25]Ma X C, An Z J, Chen L, et al. The effect of rare earth alloying on the hot workability of duplex stainless steel - A study using processing map[J]. Materials and Design, 2015, 86:848-854.

[26] Xiao X S, Li J, Xu G, etc. High nitrogen and ultra low nickel super duplex stainless steel alloys containing rare earth metals and their preparation methods: CN, 1970815 A [P]. 2007.

[27] Fellicia D M, Sutarsis, Kurniawan B A, et al. Study of sigma phase in duplex SAF 2507[J]. IOP Conference 
Series: Materials Science and Engineering, 2017, 202:012039.

[28] Wang H S , Yang J R , Bhadeshia H K D H . Characterisation of severely deformed austenitic stainless steel wire[J]. Metal Science Journal, 2005, 21(11):1323-1328.

[29] Mendonça, C. S. P, Matos R A G , Mendes J , et al. Study of formation and reversion of the martensitic phase induced by deformation of lean duplex stainless steel[J]. Journal of Nondestructive Evaluation, 2018, 37(3):64.

[30] Xie L, Huang T L, Wang Y H, et al. Deformation induced martensitic transformation and its initial microstructure dependence in a high alloyed duplex stainless steel[J]. Steel Research International, 2017, 88(12):9.

[31] Rys J , Cempura G . Microstructure and deformation behavior of metastable duplex stainless steel at high rolling reductions[J]. Materials Science and Engineering A, 2017, 700(17):656-666

[32] Ming C, Liu H, Wang L, et al. Residual stress and microstructure evolutions of SAF 2507 duplex stainless steel after shot peening[J]. Applied Surface Science, 2018, 459:155-163.

[33] Thomas S . Peak Broadening Anisotropy and the Contrast Factor in Metal Alloys[J]. Crystals, 2018, 8(5):212.

[34] Williamson G K , Hall W H . X-ray line broadening from filed aluminium and wolfram[J]. Acta Metallurgica, $1953,1(1): 22-31$.

[35] Kaoumi D , Liu J . Deformation induced martensitic transformation in 304 austenitic stainless steel: in-situ vs. ex-situ transmission electron microscopy characterization[J]. Materials Science and Engineering A, 2017, 715(7):73-82.

[36] Shrinivas V, Varma S K, Murr L E . Deformation-induced martensitic characteristics in 304 and 316 stainless steels during room-temperature rolling[J]. Metallurgical and Materials Transactions A, 1995, 26(3):661-671.

[37] Ragger K S , Primig S , Daniel R , et al. Cold pilgering of duplex steel tubes: The response of austenite and ferrite to excessive cold deformation up to high strains[J]. Materials Characterization, 2017, 128:257-268.

[38] Nagy E, Mertinger V , Tranta F , et al. Deformation induced martensitic transformation in stainless steels[J]. 
Materials Science and Engineering A, 2004, 378(1):308-313.

[39] Hilders O A, Ramos M, Peña N D, et al. Fractal geometry of fracture surfaces of a duplex stainless steel[J]. Journal of Materials Science, 2006, 41(17):5739-5742.

[40] Reick W, Pohl M, Padilha A F. Determination of stacking fault energy of austenite in a duplex stainless steel[J]. Steel Research, 1996, 67(6):253-256.

[41] Kim Y, Kim Y M, Koh J Y, et al. Evaluation of single crystal elastic constants and stacking fault energy in high-nitrogen duplex stainless steel by in-situ neutron diffraction[J]. Scripta Materialia, 2016, 119:1-4.

[42] Vitos L, Korzhavyi P A, Nilsson J O, et al. Stacking fault energy and magnetism in austenitic stainless steels[J]. Physica Scripta, 2008, 77(6):065703.

[43] Talonen J, Hänninen H. Formation of shear bands and strain-induced martensite during plastic deformation of metastable austenitic stainless steels[J]. Acta Materialia, 2007, 55(18):6108-6118.

[44] Huang C X, Yang G, Gao Y L, et al. Investigation on the nucleation mechanism of deformation-induced martensite in an austenitic stainless steel under severe plastic deformation[J]. Journal of Materials Research, 2007, 22(3):724-729.

[45] Das A, Tarafder S. Experimental investigation on martensitic transformation and fracture morphologies of austenitic stainless steel[J]. International Journal of Plasticity, 2009, 25(11):2222-2247.

[46] Hedström P, Lienert U, Almer J, et al. Elastic strain evolution and $\varepsilon$-martensite formation in individual austenite grains during in situ loading of a metastable stainless steel[J]. Materials Letters, 2008, 62(2):338-340.

[47] Seetharaman V, Krishnan R. Influence of the martensitic transformation on the deformation behaviour of an AISI 316 stainless steel at low temperatures[J]. Journal of Materials Science, 1981, 16(2):523-530.

[48] Choi J Y, Ji J H, Hwang S W, et al. Strain induced martensitic transformation of Fe-20Cr-5Mn-0.2Ni duplex stainless steel during cold rolling: Effects of nitrogen addition[J]. Materials Science and Engineering A, 2011, 
528(18):6012-6019.

[49] Neeraj T, Srinivasan R, Li J. Hydrogen embrittlement of ferritic steels: Observations on deformation microstructure, nanoscale dimples and failure by nanovoiding[J]. Acta Materialia, 2012, 60(13-14):5160-5171.

[50] Xiong Y, Yue Y, Lu Y, et al. Cryorolling impacts on microstructure and mechanical properties of AISI $316 \mathrm{LN}$ austenitic stainless steel[J]. Materials Science and Engineering A, 2018, 709:270-276. 
Table 1 Chemical composition of studied material (wt. \%)

\begin{tabular}{cccccccccc}
\hline $\mathrm{C}$ & $\mathrm{Si}$ & $\mathrm{Mn}$ & $\mathrm{P}$ & $\mathrm{S}$ & $\mathrm{Cr}$ & $\mathrm{Ni}$ & $\mathrm{Mo}$ & $\mathrm{N}$ & $\mathrm{Ce}$ \\
\hline 0.023 & 0.35 & 0.8 & $\leq 0.03$ & $\leq 0.03$ & 25 & 5.4 & 3.4 & 0.5 & 0.08 \\
\hline
\end{tabular}

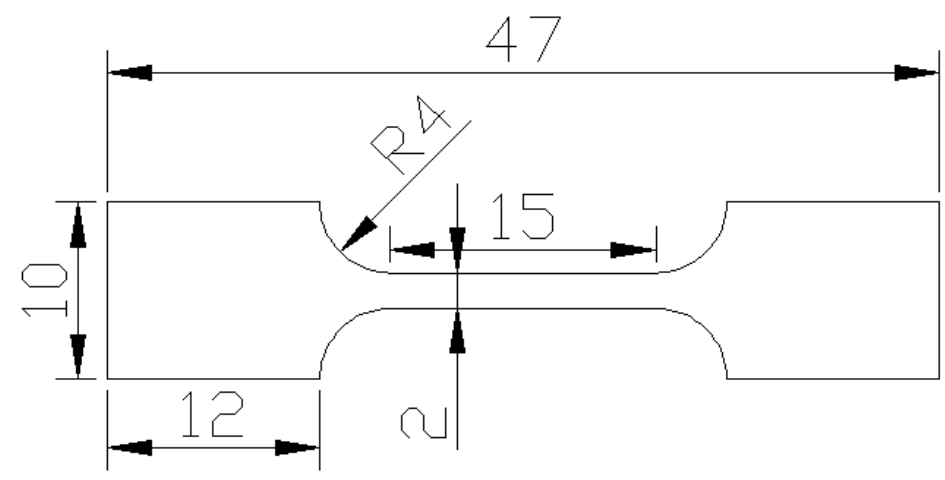

Fig. 1 The dimension of tensile sample(thickness: $0.5 \mathrm{~mm}$ ) 

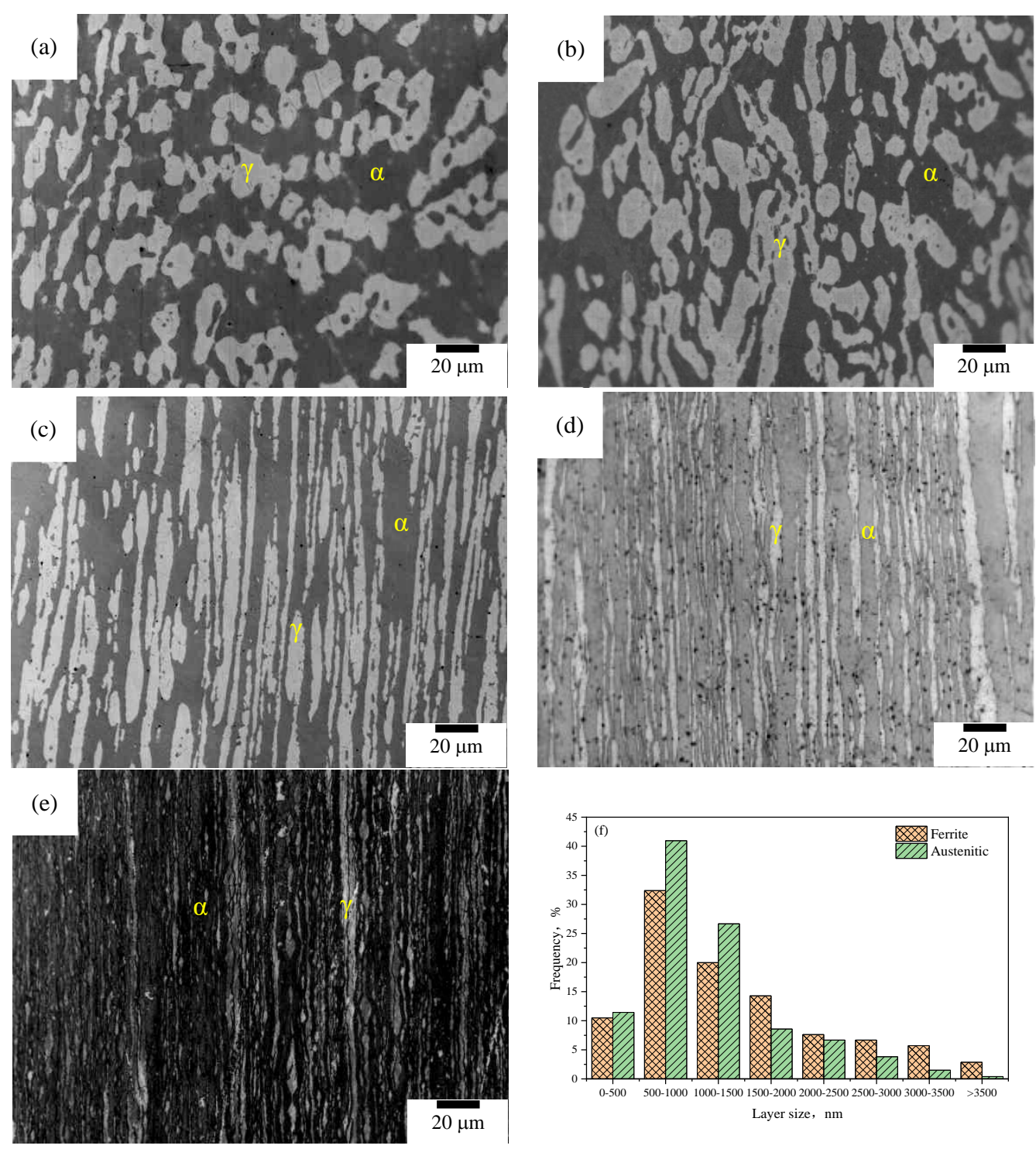

Fig. 2 Optical micrographs of Ce-modified SAF 2507 SDSS in solid solution state and cold rolled state

(a) solid solution state; (b)cold rolling by $30 \%$; (c)cold rolling by 50\%; (d)cold rolling by $70 \%$; (e)cold rolling by $90 \%$; (f)the bandwidth distribution of grains after cold rolling by $90 \%$ 

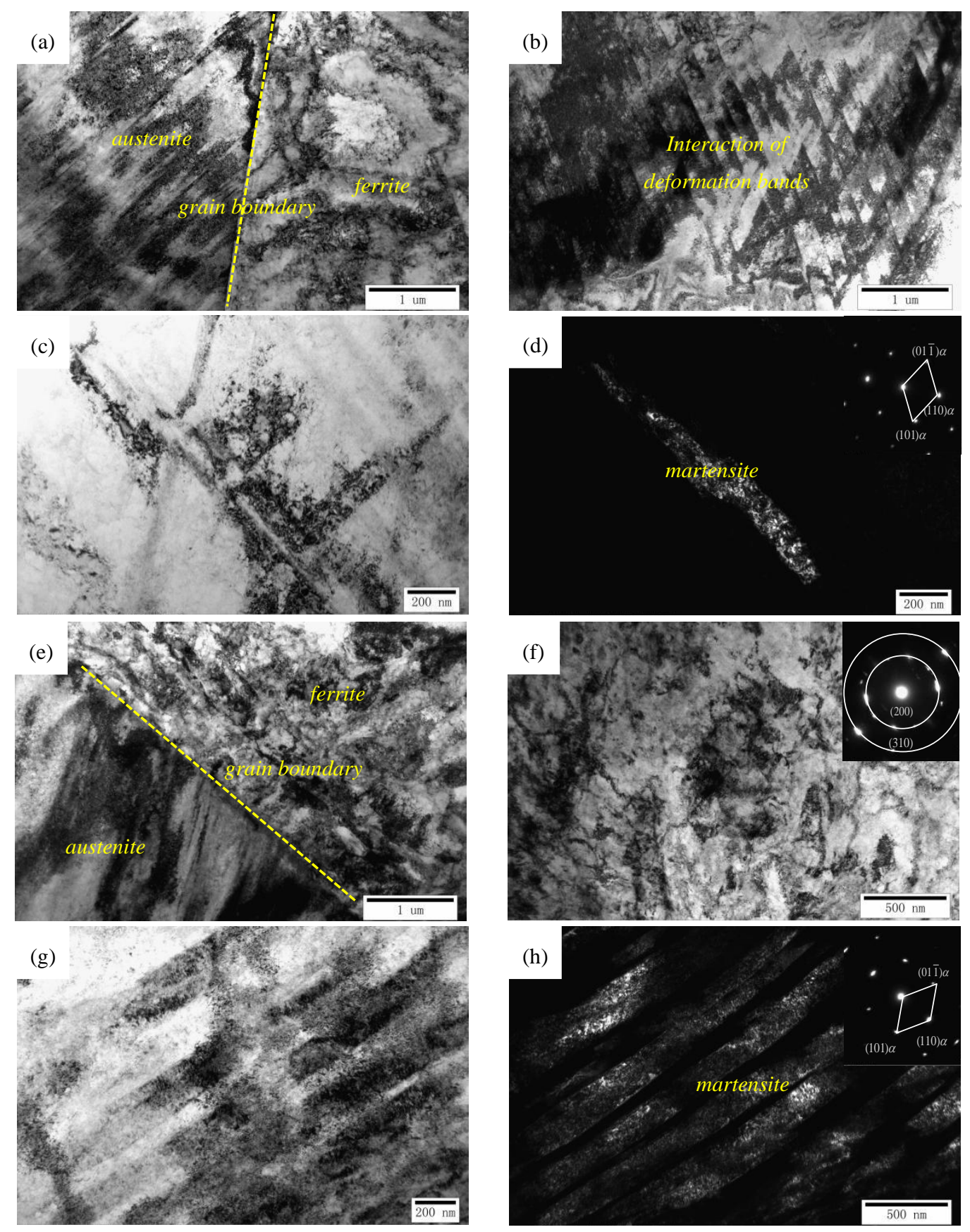

Fig. 3 Microstructure of Ce-modified SAF 2507 SDSS at room temperature cold rolling (TEM)

(a, b, c, d)cold rolling by $30 \%$; (e, f, g, h)cold rolling by $90 \%$ 


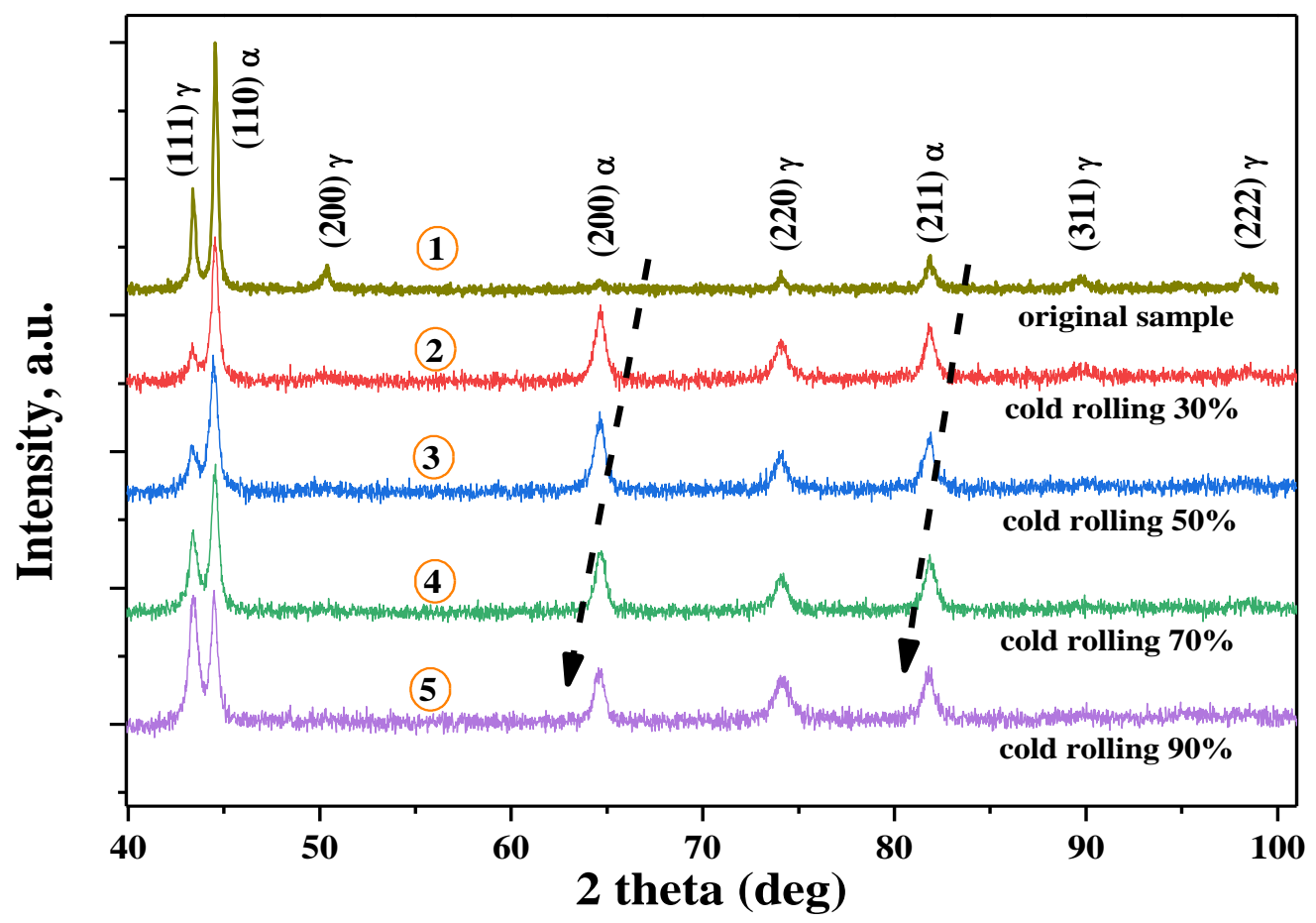

Fig.4 XRD pattern of Ce-modified SAF 2507 SDSS at room temperature cold rolling under different deformation levels.

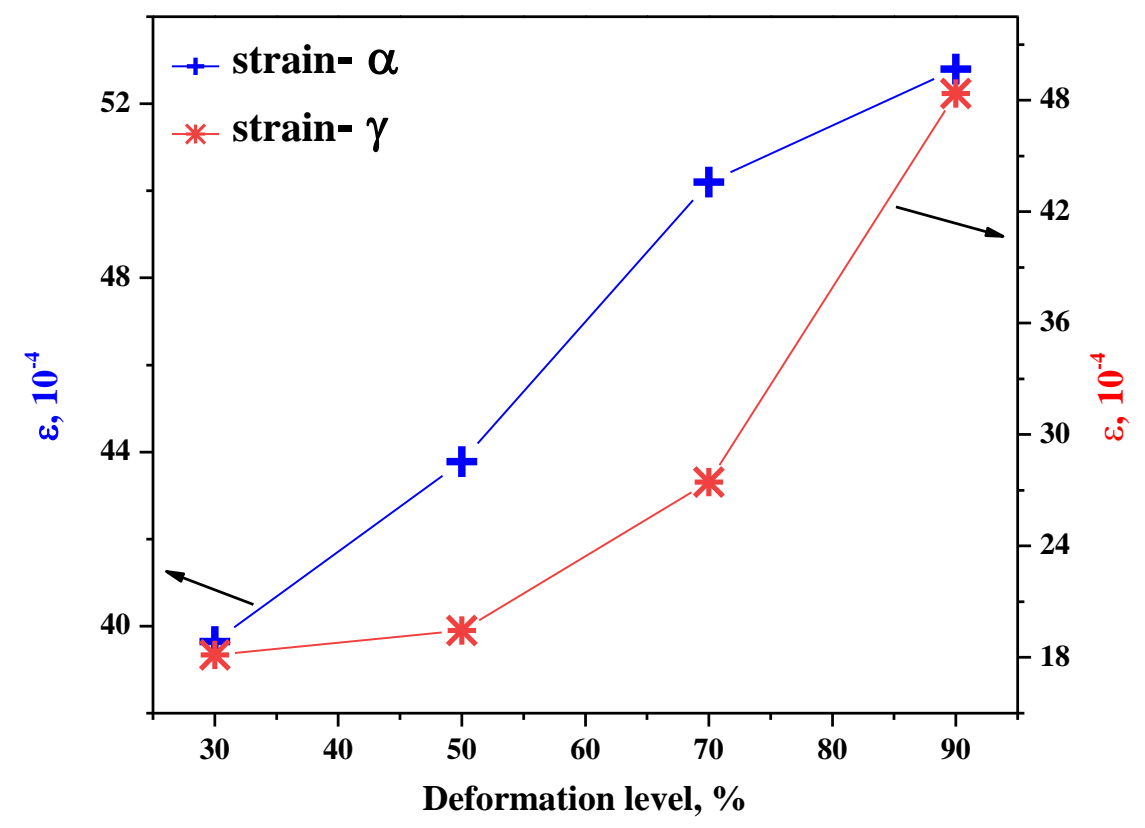

Figure 5. Strain variations as a function of deformation level of cold rolling for the two existing phases. 


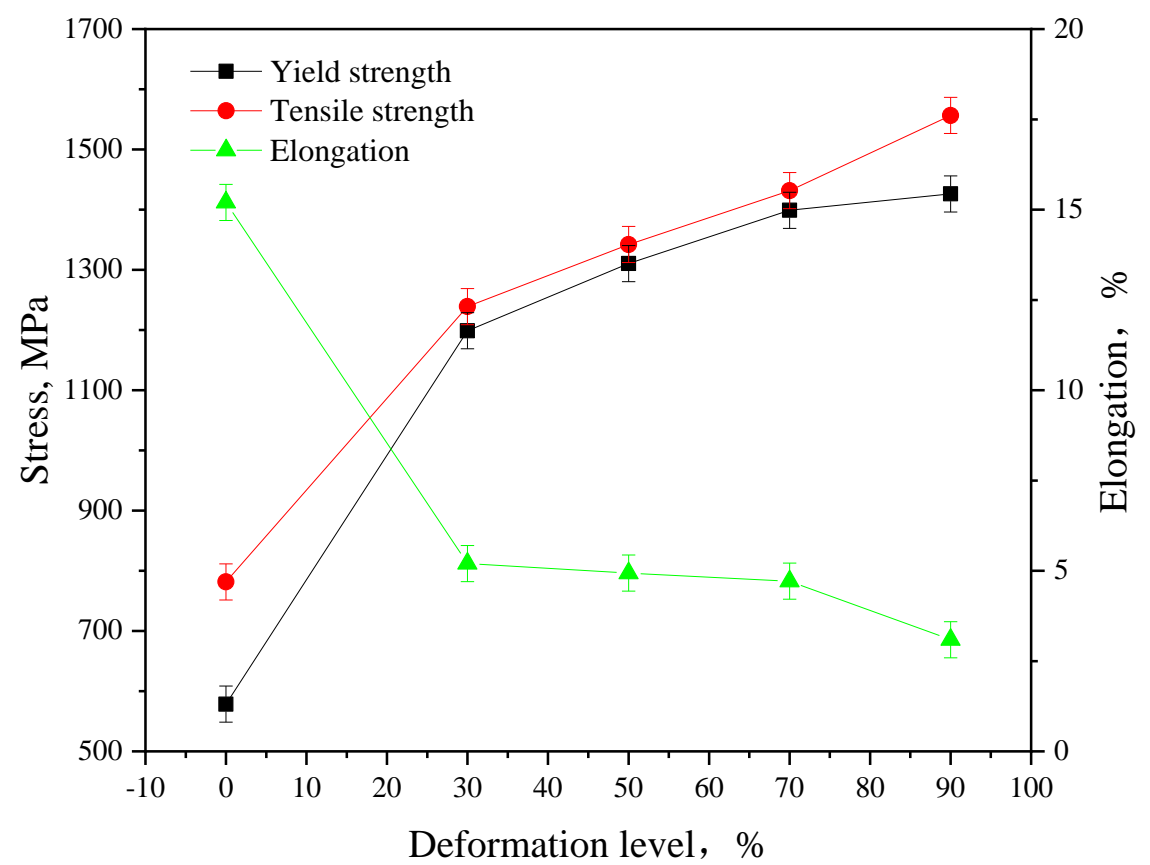

Fig.6 Mechanical properties of Ce-modified SAF 2507 SDSS at room temperature cold rolling under different deformation levels 

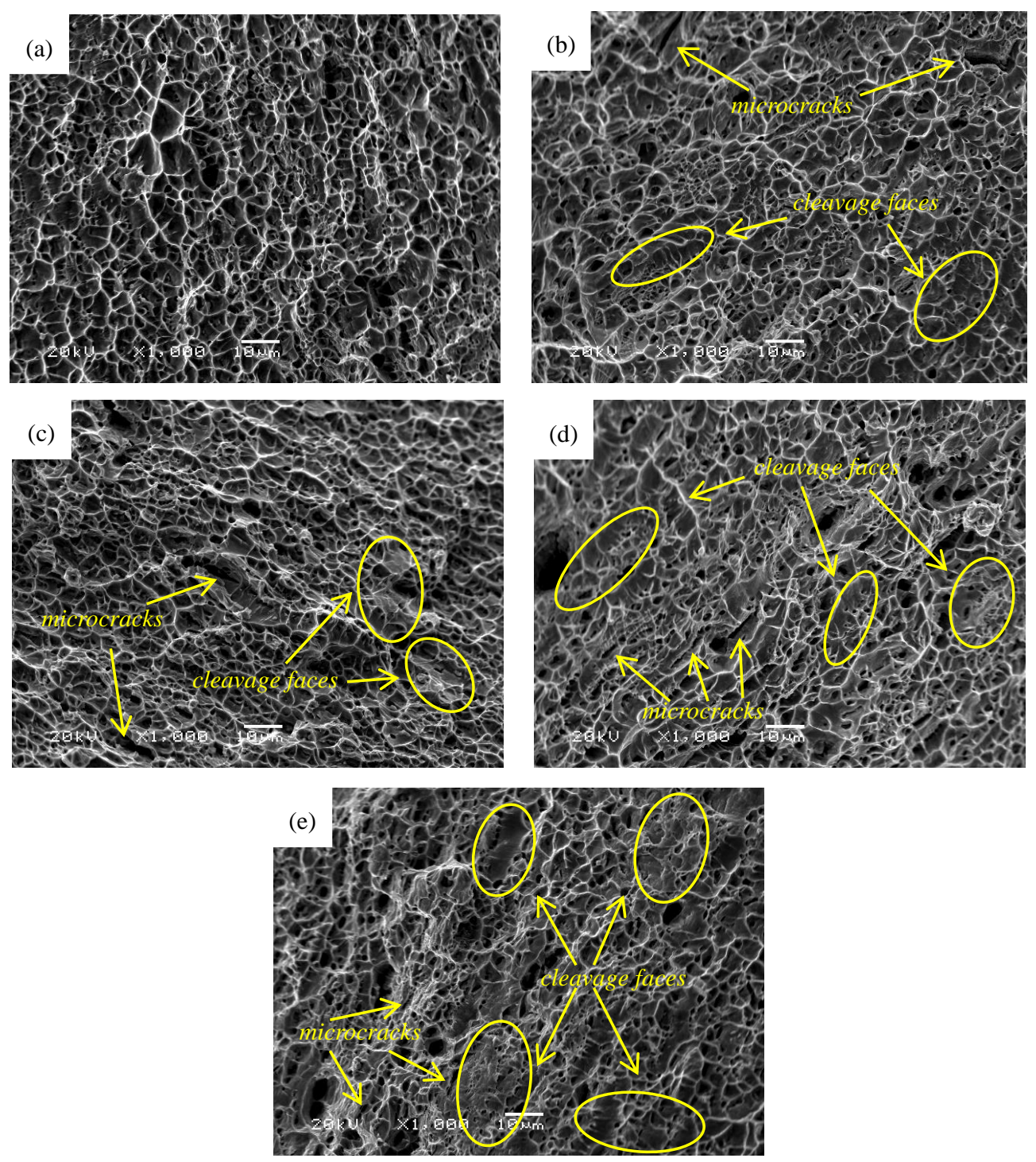

Fig.7 Fracture morphology of micro-tensile specimens of Ce-modified SAF 2507 SDSS at room temperature cold rolling under different deformation levels

(a) solid solution state; (b) cold rolling by $30 \%$; (c)cold rolling by $50 \%$; (d)cold rolling by $70 \%$;

(e)cold rolling by $90 \%$ 